Fostering learner independence through heuristic scaffolding: a valuable role for teaching assistants

\author{
*Julie Radford \\ **Paula Bosanquet \\ *Rob Webster \\ *Peter Blatchford \\ ***Christine Rubie-Davies \\ *Institute of Education, University of London, Psychology and Human \\ Development, 25 Woburn Square, London WC1H 0AA \\ **University of East London, Romford Road, Stratford, London, E15 4LZ \\ ***University of Auckland, Auckland 1142, New Zealand
}

All correspondence with respect to this article should be addressed to:

Dr Julie Radford, Psychology and Human Development, Institute of Education, 25

Woburn Square, London, WC1H 0AA., UK

Email: j.radford@ioe.ac.uk Tel: 02076126295 Fax:020 76126304 


\title{
Fostering learner independence through heuristic scaffolding: a valuable role for teaching assistants
}

\begin{abstract}
Teaching assistants currently play a key pedagogical role in supporting learners with special educational needs. Their practice is primarily oral, involving verbal differentiation of teacher talk or printed materials. In order to help students think for themselves, this paper argues that their practice should be informed by heuristic scaffolding. A substantial dataset from three teaching assistant projects was scrutinised for examples of heuristics. Using conversation analysis, the paper shows how assistance is negotiated and adjusted over a sequence of discourse. Four patterns of heuristic scaffolding are shown: heuristic modelling represents the highest level of support; heuristic questioning and prompting are jointly negotiated with the student. Self-scaffolding by students shows them taking responsibility for their own learning strategies. Implications for the school system are explored.
\end{abstract}

\section{Key words}

Classroom talk, scaffolding, teaching assistants, paraprofessionals, conversation analysis, pedagogy 


\section{Fostering learner independence through heuristic scaffolding: a valuable role for teaching assistants}

\section{Introduction}

\subsection{Background}

One of the most profound changes in UK schools over the past 15 years or so has been the huge and unprecedented increase in support staff in schools. The number of full-time equivalent Teaching Assistants (TAs) in mainstream schools in England has more than trebled since 1997 to about 190,000 (DfE, 2012). At the time of writing, (winter 2013), taken together, TAs (or teachers' aides or paraprofessionals) comprise $24 \%$ of the mainstream school workforce in England, Wales and Scotland. The rise in TAs is part of a general increase in education paraprofessionals with similar roles worldwide. Wide use of support staff has been reported in schools in Australia, Italy, Sweden, Canada, Finland, Germany, Hong Kong, Iceland, Ireland, Malta, South Africa, as well as the USA (Giangreco \& Doyle, 2007). TAs, therefore, appear to be a growing part of the school workforce in many countries, although this has been most pronounced in the UK.

One of the major policy developments to impact on the role of TAs in the UK was the National Workload agreement signed by the government and most teaching unions in 2003. The agreement led to a number of tasks previously seen as being the preserve of teachers become permissible for TAs, including planning and preparing lessons, delivering lessons, assessing, recording and reporting. This could be with individuals, groups or whole classes (DfES, 2003). The National Agreement was signed with great care taken by the government, under pressure from teaching unions, to protect the professional role and identity of teachers in the face of the potential impact of role creep. However, the role of TAs was given less attention in these negotiations. The nebulous terms used in the Agreement, such as 'supporting', 'supervising', undertaking 'specified work under the guidance of a teacher' (DfES, 2003) - as distinct from 'teaching' - were ill-defined and do not stand conceptual scrutiny, nor do they accord with observations of what actually takes place in classrooms (Blatchford et al., 2012). Yet the Agreement represented a fundamental shift in the role of the TA and raises serious issues about whether TAs should engage in traditional teacher roles. 
The extent to which TAs play a key role in teaching and learning is revealed through findings from the Deployment and Impact of Support Staff (DISS) project - the first and largest longitudinal study to analyse the impact of TAs on teachers, teaching and pupil learning, behaviour and academic progress in everyday school settings. Results from the DISS project found that TAs spent over half their six hour working day in a direct pedagogical, instructional role, supporting and interacting with pupils (3.8 hours), and this far outweighed time spent supporting the teacher and curriculum (1.4 hours) or performing other tasks (0.9 hours) (Blatchford et al., 2012).

Observations collected as part of the DISS project revealed that TAs routinely provide support to lower-attaining pupils and those with special educational needs (SEN) in one-toone and group contexts. Furthermore, it was found that such pupils are nine times more likely to have sustained (e.g., lasting longer than 10 seconds) interactions with TAs than with teachers, and are six times more likely to be actively involved (i.e., beginning, responding to or sustaining) in an interaction with TAs than with teachers.

On the basis of these results, Blatchford et al. (2012) concluded that there had been a drift towards TAs becoming, in effect, the primary educators of lower-attaining pupils and those with SEN. Teachers like this arrangement because they can then teach the rest of the class, in the knowledge that the children in most need get more individual attention. Yet, the more support pupils get from TAs, the less they get from teachers.

Worryingly, this arrangement comes at a cost to the academic attainment of vulnerable pupils. The DISS project's analysis of the effects of TA support on the progress of 8,200 pupils, across seven year groups in primary and secondary schools, found that those who received the most support from TAs consistently made less progress than similar pupils who received less TA support, even after controlling for factors like prior attainment and level of special educational needs (SEN) (Blatchford et al., 2012).

\subsection{Pedagogical role of the TA}

Following the DISS project, it has been suggested that there needs to be a debate about the appropriate pedagogical role of TAs (Webster et al., 2010). Despite the UK coalition 
government's drive to close the attainment gap between disadvantaged pupils and their peers via the Pupil Premium funding, and the plan to give parents of pupils with a statement of SEN control over their child's SEN budget, TAs are largely absent from the discussions about policy and practice.

The likelihood, however, is that TAs will continue to be pivotal to how schools meet the needs of children with SEN (The Sutton Trust, 2012). As a consequence, important questions are raised: (i) what is effective TA support for children with SEN; (ii) how can support be delivered by staff who do not have the professional qualifications and experience of teachers?; and (iii) how can teachers, as managers of TAs, prepare them for a pedagogical role?

In terms of TAs' practice in the classroom, successful outcomes are associated with certain pre-conditions: tasks are delegated by the teacher and specific training is given in instruction as well as in behaviour management (Causton-Theoharis, 2007). In reality, the TAs' role is primarily oral, conducted on a moment-by-moment basis (Radford et al., 2011) and often involves verbal differentiation of teacher talk or printed material (Blatchford et al., 2012). Whilst TAs are ideally placed to provide optimum, contingent support for the learner, all too often, their interactions with pupils tend to focus on task completion rather than developing understanding (Rubie-Davies et al., 2010). TAs do not know how to make the best use of the extended, more frequent interactions they have with pupils and this could have longer-term implications for creating passive learners (Radford et al., 2011).

In this paper we argue that, in order to deliver effective support, TAs' pedagogical practice should be informed by relevant theories of teaching and learning. Such theories should underpin not only how TAs design their turns (the repertoire of strategies that they use), but also how they adapt support for the learner over a sequence of discourse. Given TAs' extensive opportunities for individualised support, our candidate theory is scaffolding.

\subsection{Scaffolding}

TAs who were interviewed as part of the DISS project often described their role as providing scaffolding for pupil learning; however, this conceptualisation of scaffolding is ill-defined and at variance with how we apply the term in this paper. Scaffolding has its origins in the 
sociocultural theory of Vygotsky. The theory proposes that, through social interaction with others at the intermental level, young children develop higher mental functions such as thinking and reasoning (Vygotsky, 1981). To be effective, such social exchanges must lie within children's 'zone of proximal development' (ZPD), that is, the distance between what they can accomplish on their own as opposed to what they can do with the help of more capable others, such as parents (Vygotsky, 1978). The ZPD was developed further and taken from parent-child interaction and applied to educational contexts.

One of the strongest criticisms of scaffolding, as originally conceived, is that it represents an asymmetric view of adult-child interaction whereby the scaffolder constructs the scaffold alone and presents it to the child in the role of 'novice' (Daniels, 2001). Many have since argued that the child needs to be an active participant in the interaction; Newman, Griffiths and Cole (1989) made the case for a 'construction zone' that is created in the ZPD through negotiation between a more advanced partner and the learner. How the zone is created, through interaction, has been the topic of many studies across different domains of learning.

So, what should a theory of scaffolded instruction for TAs look like and which concepts are important? An extensive review of scaffolding research concluded that three fundamental principles were commonly found across studies (Van de Pol, Volman \& Beishuizen, 2010). As shown in Figure 1, the key characteristics are contingency, fading and transfer of responsibility. The first concept, contingency, refers to how support is adjusted in the moment, either tailored to the learner's current level of performance or (ideally) to a slightly higher level. For a TA, an example of such a move would be to use a diagnostic question such as 'What do you think $\mathrm{x}$ means?' to ascertain the student's current level of understanding. After listening carefully to the child's response, if the TA pitches the next turn at a slightly higher level, it is possible to claim that she or he is interacting contingently.

Figure 1 Conceptual model of scaffolding

Figure 1 shows how the other two principles of scaffolding, fading and transfer of responsibility, are closely interrelated. In the case of fading, the TA would gradually withdraw the scaffold by decreasing support for the student and withdrawing it altogether when it is no longer needed (Van de Pol et al., 2010). How and when to fade within a 
sequence of discourse is clearly a sensitive matter for TAs, as it rests on their appreciation of the learner's competence in given tasks. If fading is successful, responsibility will be transferred to the student. Van de Pol et al. (2010) interpret responsibility in the broadest sense as relating to cognitive or metacognitive activities, as well as affect. Yet, while use of contingent strategies by teachers is fairly common, handover of responsibility is much harder to demonstrate, not only in large classes (Myhill, 2006), but also in smaller groups (Blatchford et al., 2003).

Many descriptive studies have examined what scaffolding looks like in practice, especially in literacy tasks; by contrast, most of the effectiveness studies have been conducted in science and mathematics lessons (Van de Pol et al., 2010). Observational research has provided thick descriptions of the scaffolding process (Hacker \& Tenent, 2002; Maloch, 2002; Myhill \& Warren, 2005). On the other hand, coding schemes have been widely used and are helpful for understanding the nature of the strategies used by the adult. A typical list might include modelling, instructing, explaining, questioning, prompting and/or feeding back (Mercer et al., 2004; Meyer \& Turner, 2002).

To portray the degree of support afforded by a scaffold, some researchers helpfully conceptualise strategies in terms of a hierarchy. For example, Pentimonti and Justice (2010) distinguish between high support moves where the adult's assistance is most structured (i.e. co-participating, reducing choices and eliciting) and low support devices where assistance is minimal (generalising, reasoning, predicting). They found that $96 \%$ of the strategies used by early years' teachers offered low support which suggests that they display a limited repertoire of the higher support moves which, they argue, are necessary for children with special educational needs. Furthermore, the authors claim that adjusting the level of support is highly skilful; to teach contingently the adult requires a good understanding of the curriculum, a theory of the task as well as a theory of the students' needs. Once again, the question is raised regarding what can reasonably be expected of TAs, given that they do not possess the same level of subject and pedagogical knowledge as teachers.

This paper proposes heuristic scaffolding as the key element for inclusion in a candidate theory of TA pedagogy. Such a theory deals with how students can be helped to internalise their own learning strategies. Heuristic is a term used in education, defined by the 
Cambridge online dictionary (2012) as: 'a method of teaching, allowing students to learn by discovering things themselves, learning from their own experiences rather than by telling them'. The purpose of heuristic scaffolding is to empower students by developing their awareness of relevant approaches to problem-solving (Holton \& Clarke, 2006). Described in this way, heuristic scaffolding is closely related to metacognition.

Heuristic scaffolding may be operationalised through the various techniques described earlier: questioning, modelling and prompting. Yet, the use of these strategies by a TA would not guarantee that fading and transfer of responsibility have occurred. Any contingent turn depends on several things: (i) its design; (ii) its position in the sequence of discourse with respect to what the child is doing; and (iii) how support is adjusted over time. In order to offer the micro analysis needed to address these issues, our study uses conversation analysis (CA).

The first advantage of using CA is the level of detail afforded by a moment-by-moment analysis. To be 'heuristic', the design of the TA's turn must include a learning strategy relevant to the subject area of the lesson; for example, the TA modelling how to sound out a word during a reading task (Bosanquet, 2012). The second benefit of CA is a sequential analysis, which takes account of the students' turns as well. Research shows that TAs work with students with SEN who typically display 'troubles' (e.g., an incorrect response or a silence when searching for an answer) (Radford, 2010a; 2010b). In the next turn, if the TA simply gives the answer, this would not provide a contingent learning opportunity. A more effective move, because it gives responsibility to the learner, is to ask them to explain their working out strategies. Finally, another important contribution of CA is that a sequential analysis allows the analyst to show how the TA adjusts support over time. During a sequence of turns, the TA might alter the design of the heuristic turn either to increase support or reduce it, tailoring it sensitively depending on the responses of the learner.

As the ultimate goal of scaffolding is to transfer responsibility to the learner, TAs would ideally fade their support so that students take control of their own learning. The use of selfscaffolding questions by the child, such as 'Have I checked it?', provide strong evidence of a student taking responsibility for a learning strategy (Holton \& Clarke, 2006). In our view, the fostering of self-scaffolding is an admirable aim for the TA when working in both one-to-one 
and group teaching contexts as it avoids known problems of TAs acting in ways that give preeminence to the completion of tasks.

Although scaffolding is a widely known and extensively researched concept, it has not yet been studied with regard to TA interactions. Using CA, we aim to set out detailed examples of how the TA provides heuristic scaffolding that targets learning strategies in mathematics and literacy lessons. The research questions are:

1. How are the various strategies designed and do they have different implications for student involvement?

2. Is there evidence of fading of support and transfer of responsibility?

3. Is there evidence of self-scaffolding by students?

To address the first question, we closely examined the linguistic design of each strategy in the database; for example is it a question or an imperative? As we show, each type of design has a different effect on student participation. We distinguish high support, when the learner is in need of more assistance because of troubles (heuristic models), from lower support strategies that have potential to foster transfer of responsibility (heuristic questions and prompts). Finally, we illustrate independent use of strategies by students, a marker of successful transfer of responsibility. The discussion explores the relationship between models, questions and prompts. It will also examine the implications for the school system in preparing TAs to use heuristic scaffolding.

\section{Methodology}

\subsection{Design and sample of interactions}

This is a descriptive study of naturally-occurring classroom interactions involving TAs. Theoretical sampling of extracts was made in order to illustrate the hierarchy of heuristic scaffolding, allowing theory to be generalised from a small number of cases (Corbin \& Strauss, 2008). A grounded approach to the analysis was taken, informed by the procedures of conversation analysis.

To generate a suitable dataset, TA interactions from three projects was closely scrutinised. A. The DISS project 
Audio recordings of adult-pupil interactions were collected in 2007/2008. Forty-two recordings were made in 15 schools (8 primary, 7 secondary) of the teacher and the TA during the same lessons. 16 teacher-TA pairs were chosen for transcription and selected for further study (see Radford et al, 2011; Rubie-Davies et al., 2010). The selection was purposive in so far as there were two primary (year 5) and two secondary classes (year 8) but, otherwise, it was random. The schools were spread geographically within England and were diverse in terms of their student intake. Most of the TAs in the DISS study were supporting in class rather than doing interventions for which they had been trained.

\section{B. The Effective Deployment of Teaching Assistants (EDTA) project}

This was a follow-up study to the DISS project and was conducted over 2010/2011. The project involved ten schools (six primary, four secondary) in two local authorities in England. Eight audio recordings were made in order to evaluate the extent to which key features of TA-to-pupil talk had improved as a result of involvement in the project. For more information, see Webster et al. (2012). The situation regarding training and preparation for TAs in the EDTA project was consistent with the picture described in the earlier DISS study (Webster et al., 2012).

\section{The Interactions of Teaching Assistants in Primary (ITAP) schools project}

Twenty-two video-recordings were made of small group literacy intervention sessions with 56 and 7-8 year-olds (Bosanquet, 2012). The TA leading each of these groups used materials provided by either the local authority or national Early Literacy Support materials (DCSF, 2007) or national Additional Literacy Support materials (DfEE, 1999). The materials were designed to develop the reading, writing and spelling skills of pupils who were at risk of falling behind their peers. All the TAs involved had attended between one and two days training in relation to the intervention materials.

Information about the children is presented in Table 1 and pseudonyms have been used.

Table 1 here

2.2 Procedure and process of analysis 
The digitised recordings were transcribed. Members of the research team repeatedly viewed or listened to the recordings and read the transcriptions. A selection of extracts was made, driven by criteria related to scaffolding and heuristics, and focusing on both literacy and mathematics lessons. Similar sequences were compared and contrasted, using constant comparison, until robust patterns emerged. Rich descriptions of each extract were made, paying attention to features of their design and position in the sequence of turns.

Despite an extensive search, the majority of lessons yielded very few examples, which suggests that use of heuristics is not widely practised by TAs. Our aim, therefore, is to develop theory and illustrate potential practice for TAs rather than exactly represent current practice in schools. For each extract, interpretations are drawn out, in terms of their relevance for heuristic scaffolding, the extent to which the TA fosters student involvement and provides opportunities for them to take responsibility for thinking about their own learning strategies.

\section{Results}

The findings are set out in four main sections, showing evidence from both mathematics and literacy sessions. The heuristic data are sub-divided into three types of strategies, according to the degree of support afforded by the TA: a) heuristic models b) questions and c) prompts. The fourth section shows students' independent use of self-scaffolding. First, we demonstrate heuristic models. The key analytical point that distinguishes models from questions and prompts is that the TA tells the children of the learning strategy as opposed to jointly negotiating the strategy with them which justifies the decision to term it a high support move in terms of scaffolding theory.

\subsection{Heuristic model (high support)}

Extract 1 takes place 10 minutes into the lesson when the students are working on their maths problems and the TA is supporting individuals and different (small) groups in turn when they need help. In this lesson, owing to the TA role, it is not uncommon for the children to ask the TA questions when they are experiencing difficulty (known as 'trouble' in CA). The arrowed turn in extract 1 is the key analytical feature, showing the TA using a heuristic model.

\section{Extract 1}


1 TA It is well done, yeah, 34 it definitely is, isn't it?

2 Rob What is the model?

3 TA Model, model? What do you think that is?

4 Rob Mode?

5 TA Yes. What is mode anyway?

T 6 Rob Uhh

$\rightarrow 7$ TA Mode (.) most. It sounds similar, doesn't it?

8 Rob Yeah. Most, so that would be eighteen.

9 TA Yes it would.

$\mathrm{T}=$ trouble

Rob, in line 2, asks the TA about the 'model' which is an error, given that his current mathematics problem concerns finding the 'mode'. The TA puts responsibility back to Rob in asking what he thinks it is, thus withholding giving the definition herself. In the next turn, Rob self-corrects to 'mode' which the TA confirms and puts the question, again, back to him. Line 6 is troublesome in so far as Rob does not supply the TA with an answer. At this point the TA has different options: one possibility is to give Rob the full answer straightaway, for him to repeat, but this would risk closing down his active involvement. Instead, she models a mnemonic strategy, which includes a phonological clue, to help him recall the answer (line 7). Rob repeats her clue and successfully supplies the correct answer.

It is notable in this sequence that, even though the TA is treated as the expert by the student who asks her for the definition, she creates several opportunities for him to take responsibility. The heuristic model can be potentially used by him to self-scaffold, in order to attempt to tackle the problem independently in the future, when she is not there. Heuristic models afford relatively high support on the part of the TA because she is telling him the strategy as opposed to getting him to recall it. In this extract it is used in the context of repair when the student is stuck and needs additional help. The extract amply demonstrates contingency in action but not, in itself, transfer of responsibility.

Extract 2 shows a sequence of three heuristic modelling moves, indicated by the arrowed turns. The extract is taken from a literacy session which is focused on reading. Members of 
the group are taking it in turns to read aloud. The sentence on the page being read is 'Pete went back to play with his computer game'.

\section{Extract 2}

T 1 Ryan Pete went back to play what (0.6) his (0.5)

$\rightarrow 2$ TA Read that first word again

3 (points at word 'with')

$4 \quad$ What does that word say?

T $5 \quad(5.0)$

$\rightarrow \quad 6 \quad$ TA Sound it out Ryan

7 Ryan w i t h

T $8 \quad(1.8)$

$\rightarrow \quad 9 \quad$ TA You know those two sounds together make a 'th' sound don't they?

10 So the word is $\mathrm{w}$ i?

11 Ryan with

$\mathrm{T}=$ trouble

In line 1 Ryan reads the word 'with' as 'what', and demonstrates awareness that the sentence does not make sense through the pauses before and after the word 'his'. However, he requires a prompt from the TA (line 2) to reread the word creating the trouble (i.e. to use rereading as a strategy for making sense of text). It becomes clear by the silence in line 5 that decoding the word is causing trouble for Ryan, and so the TA provides a further model, this time of a strategy to tackle unknown words (to sound out the word). However, Ryan enunciates each individual phoneme, rather than the digraph 'th' at the end of 'with'. This does not solve his problem of understanding the word (indicated by the pause in line 8 , where a blending together of the whole word would be expected). A further heuristic model is provided by the TA in line 9 (drawing on known knowledge of diagraphs), followed by a prompt to support Ryan in using this model (the beginning of the word is sounded out by the TA, leaving Ryan to complete the word by inserting the digraph). The word is correctly stated by Ryan in line 11, showing receipt and use of the TA's model. 
Each heuristic model used in Extract 2 is a relevant strategy at that contingent moment in the sequence. They model ways in which Ryan might tackle similar sentences which do not make sense to him, and decode further unknown words. However, the models afford a high level of support since they are very much TA-led. They therefore do not require Ryan to draw on his own repertoire of strategies in relation to comprehension and decoding.

\subsection{Heuristic question (mid support)}

In extract 3 (line 3), the arrowed turn demonstrates the TA's use of a heuristic question. Such a question nominates a strategy whilst simultaneously asking the learner to recall part of it. As such, a heuristic question lies in the negotiated zone between the scaffolder and the learner. The sequence is taken from the same mathematics lesson as Extract 1.

\section{Extract 3}

1 TA OK, so what would the mode be from that list?

$\mathrm{T} 2$ Scott What's the mode mean again?

$\rightarrow 3$ TA Mode. Mode, what does it sound like?

4

5 TA Mode (.) it sounds like (.) most? Mode yes?

6 Scott Oh all right. Most common.

7 TA Yes.

8 Scott It would be (.) five.

9 TA Yes, well done.

$\mathrm{T}=$ trouble

The TA begins this episode by asking Scott a question about the mode. As he is in trouble because he is unable to give the required answer, he initiates a repair by asking her for a definition. The TA has the option next of supplying an explanation but, instead, opts to return a question to Scott, thus increasing his responsibility for thinking about the answer. The question is heuristic because it concerns a learning strategy that could help the student to remember the answer on his own. The TA allows Scott some thinking time to recall the clue but, as his response is unforthcoming, she supplies the model of the hint herself in line 5 . At 
this point the clueing is sufficient for Scott to recall the rest of the strategy as he is able to say 'most common'.

In terms of scaffolding, this is an interesting sequence. The TA first of all uses a lower level device (a heuristic question) and when this fails, she contingently adjusts her support over time to a higher level (a heuristic model). Yet, even the model affords Scott a degree of independence because it is a partial clue and which requires him to retrieve the full definition. The sequence is exemplary practice if the pedagogical goal is to foster student independence, as it clearly operates very differently from supplying the answer immediately.

The following literacy extract similarly demonstrates the use of a heuristic question, followed by a further question in order to lead the pupil to the next step in the process of spelling a word (from identifying to applying). Each group member is taking it in turns to spell a word of a sentence that they have composed together. The TA is writing on the board.

\section{Extract 4}

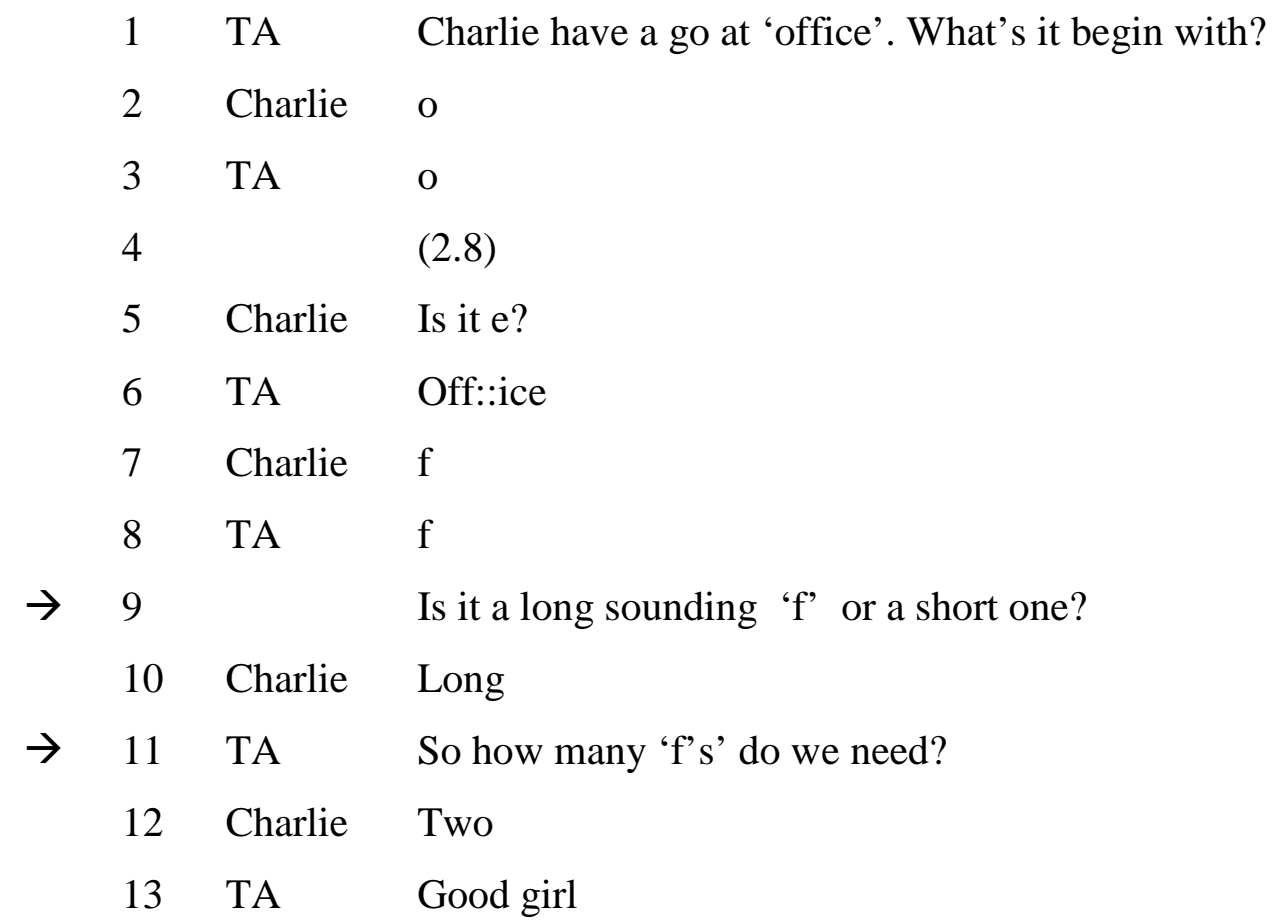

Following instructing Charlie to 'have a go at office', the TA immediately provides a model of how to approach the spelling of the word ('What's it begin with?'). The model is given 
before there is any indication that Charlie is unable to recall the strategy on her own. Charlie spells the first letter ' $O$ ' correctly, which is repeated by the TA. The rising intonation and the use of 'is it' in line 5 indicate that Charlie has already identified that her guess at the second letter may not be correct. A clue is provided by the TA in the next turn, who repeats the word 'office' with emphasis on the ' $f$ '. Charlie notices the sound ' $f$ ' and offers it to the TA, who accepts it with a repeat. The TA then uses a heuristic question which supports the identification of the long sound ('Is it a long sounding f or a short one?'). The question is a necessary precursor to her follow-up, 'So how many f's do we need?', which supports Charlie in drawing on her knowledge of long and short phonemes to identify that there are two f's in the corresponding grapheme. The questioning has therefore required Charlie to draw on her knowledge of phonemes to identify the sound as a long one and then apply her knowledge of phoneme/grapheme correspondence to spell the next part of the word.

\subsection{Heuristic prompt (low control)}

The third type of heuristic scaffolding, illustrated in the next two extracts, gives the child even more responsibility than our earlier examples. In (5), rather than the TA articulating a model of the strategy, or nominating the technique, she requires Josh to recall it entirely on his own. The exchange takes place in the second half of the mathematics lesson, referred to earlier, when a new problem is being discussed concerning finding the 'range'.

\section{Extract 5}

1 TA Oh well done. You've done your mode.

$2 \quad$ So what would your range be?

3 Josh For what?

4 TA For fitness.

T 5

$\rightarrow \quad 6$ TA How do you find your range?

7 Josh Get the biggest number.

8 TA Yep.

T 9 Josh And divide by the smallest number. 
10 TA That's not your range

T 11

$\rightarrow \quad 12$

From the biggest number:::

$\mathrm{T} 13$ Josh Divide by the smallest number.

14 TA Not divide.

15 Josh Take away.

16 TA Yes, that's the one. Well done.

$\mathrm{T}=$ trouble

Having completed the 'mode' problem, the TA moves on to ask Josh about the 'range'. Josh (line 3) clarifies the specific question that is being discussed, that is, the range of students' fitness scores. The first trouble arises at line 5 where there is a silence which the TA treats as Josh being unable to select a score. In the next turn, the simplest solution would be for her to tell him the answer but that would increase Josh's dependence on her. Instead, the question that she uses equates with a heuristic prompt because it invites him to tell her the working out method. This is a low-assistance move as it is designed as an open question, which affords him maximum responsibility for thinking of the answer. Indeed, it is pitched contingently because Josh is able to state the first part of the working out procedure: 'Get the biggest number'. The TA treats this as a partial response, offering confirmation, but allowing him to continue at line 9: 'And divide by the smallest number'. Josh has, in fact, attempted to verbalise a heuristic device that he could use to self-scaffold in the future. There is only one problem, which is 'divide'. The TA recognises this issue and gives him very clear feedback that his verb is incorrect. She pauses for a moment, where he could self-repair, but he does not. At line 12, she repeats his idea from line 7 but does not complete the sentence grammatically, stretching the final sound in anticipation of his completion: 'number:::'. Designed in this way, the turn works heuristically, prompting Josh to complete the sentence by self-correcting his error, 'divide'. Josh fulfils the job of completing the sentence but he fails to self-repair his error. It takes one more feedback move from the TA before he arrives at the correct answer. Despite the child's difficulties in this extract, it is notable how the TA persists in using low level strategies that afford transfer of responsibility to the learner. Indeed, it is evident that Josh has been actively involved and that there is a positive outcome for him. 
The following extract demonstrates that querying the previous turn can also act as a heuristic prompt to encourage the child to draw on their own resources to rethink their response. The group is taking it in turns to read aloud. The sentence being read by Clare, which refers to a toad, is 'He croaked and groaned.'

\section{Extract 6}

$\begin{array}{cccc}\text { T } & 1 & \text { Clare } & \text { He crocked } \\ \rightarrow & 2 & \text { TA } & \text { Crocked do you think that makes sense? } \\ & & & \text { N }[\text { o } \\ 4 & \text { Clare } & \text { [Oh croaked } \\ 5 & \text { TA } & \text { He croaked good } \\ 6 & \text { Clare } & \text { He croaked and growled } \\ \text { T = trouble } & \\ \text { [ = square bracket denotes overlap }\end{array}$

The word 'croaked' is read by Clare as a non-word 'crocked' (an error). In line 2 the TA repeats Clare's turn ('crocked') and queries the sense of this ('Do you think that makes sense?'). Rethinking the word requires Clare to draw on her knowledge of vocabulary relating to toads, and she is able to repair the word herself without any higher level scaffolding in line 4. Turns that ask the child to question the sense of the previous turn place the responsibility with the child, therefore encouraging independence and the development of self-scaffolding strategies. Such turns also allow for further low level scaffolding by the TA, or an escalation of heuristic scaffolding (to questioning or modelling).

\subsection{Self-scaffolding}

Our data, interestingly, show students very occasionally using self-scaffolding spontaneously in the same lessons where heuristic moves are used by the TA. Self-scaffolding is extremely important because it provides evidence of transfer of responsibility from the TA to the learner. The child must have listened to the heuristic strategies offered by the adult in order to use them without prompting or modelling in the prior turn. It is vitally important that the TA recognises a self-scaffold in use and has the skills to respond contingently. For example by 
extending the student's turn in (7), we demonstrate her taking an important opportunity to make a contingent turn.

\section{Extract 7}

1 TA Well Bryn what does question two ask you to do?

2 Sam This is going to be hard because they're all mixed up.

3 Bryn You have to put all the ages in order.

4 TA Yeah. What order? From what?

5 Bryn Sixteen seventeen.

6 TA Yeah. So that's good.

7 Bryn Seventeen.

$\rightarrow \quad 8$ Sam I'm just going to write them down.

9 Bryn Eighteen.

$\rightarrow \quad 10$ TA Are you? And then re-arrange them? Yes.

11 Bryn Nineteen.

$\rightarrow 12$ TA And it's always a good idea to check them.

$\rightarrow \quad 13$ TA Count them and check that you've got them all.

In extract (7), line 8, Sam says aloud his writing-down strategy to help him solve the problem. As the children are working in a small group, this provides peer scaffolding (in the form of a heuristic model) for Bryn. The TA, in her follow-up turn, extends Sam's selfscaffolding idea. In fact, she makes several suggestions as to how the students could work out and check their answers. These examples of heuristic models could be valuable for the students when they are working on a similar task on their own in a future lesson and might even transfer to other learning situations.

Extract 8, similarly, shows Eve articulating the self-scaffolding strategy that she is using in a literacy lesson. The group has been taking it in turns to select individual pieces of paper to place on the table to try and form a complete sentence. Eve has the last piece of paper to place.

Extract 8 


$\begin{array}{cccl} & 1 & \text { TA } & \text { Next word. } \\ & 2 & \text { Eve } & \text { (hand up) } \\ 3 & \text { TA } & \text { Eve } \\ 4 & \text { Eve } & \text { (reads and moves each piece of paper along in turn) } \\ & 5 & \text { TA } & \text { Quickly Eve. } \\ 6 & & \text { [It's really difficult? } \\ 7 & & \text { [(indicates remaining piece of paper) } \\ & & & \text { What's the last word? } \\ & 9 & \text { Eve } & \text { (puts paper in place) } \\ & 10 & \text { TA } & \text { What is it? } \\ & 11 & \text { Eve } & \text { I was just checking it. } \\ 12 & \text { TA } & \text { You were just checking it. }\end{array}$

The actions at line 4 show that Eve is reading the sentence for sense, one word at a time, before placing the last piece of paper. Indeed, at line 11 she declares her strategy aloud in response to the TA's clueing, prompting and questioning. Checking for sense during the process, rather than just at the end, is an appropriate self-scaffolding strategy, and would be likely to provide a model for others in the group. In this extract, Eve's non-verbal checking actions are not noted by the TA as a useful device, but the verbal explanation is acknowledged.

\section{Discussion}

The research concept of heuristic scaffolding for TAs is new. We presented examples of TA talk to illustrate the key dimensions of our theoretical model of heuristics. This repertoire of possible strategies could be used by TAs, in core subject areas, given sufficient training in the use of scaffolding. If TAs are to play pedagogical role, under close teacher supervision, they could be supported in the use of scaffolding in order to assist the learning of vulnerable students.

In order to develop our theory, we further sub-divided Holton and Clarke’s (2006) framework into three types of heuristic techniques (models, questions and prompts) so that we could explore how such designs have different implications for student involvement. The use of 
modelling and systematic prompting has been proposed by others for the instruction of learners with disabilities (Spooner, 2012). However, these approaches are informed essentially by a behaviourist perspective, whereas our work is influenced by Vygotsky (1978) and scaffolding theory (Holton \& Clarke, 2007) and places central importance on the contingency of each adult turn.

In terms of affording high or low support to the learner, a tentative hierarchy of heuristic scaffolding is presented in Figure 2. It is vital that TAs have the full range of oral techniques at their disposal in order to adjust their support contingently. A heuristic model might be used when more assistance is required, for instance because the student is in trouble and needs to be told the strategy directly. In contrast, when the student has more experience of the problem, a prompt might be appropriate to get the learner to recall a method that has previously been taught. Heuristic questions offer mid support because they are negotiated between adults and children. By offering a partial heuristic clue in the context of a question, the TA requires the student to think and thereby fosters their involvement.

Figure 2 Hierarchy of heuristic scaffolding

As well as familiarity with the oral techniques, it would also be helpful for TAs to understand their different implications for the learner over a short sequence of discourse. As a first tactic, TAs might offer low support (a heuristic prompt or question), to see if the student knows the strategy but, in response to difficulty, they could increase assistance and provide a model. First of all, the TA could use a low support move such as a non-verbal prompt, if there was a picture clue or written word, or a request for repetition (Radford, 2010a). If the student was still in difficulty, a specific design might be needed, such as a Wh-type question (extract 7), or the offer of a model or 'candidate' idea (see Radford, 2010b, for more examples).

The heuristic model presented here, however, is necessarily parsimonious. To make it manageable for ease of communication and for training purposes, we have reduced it to a few components. As a result, the proposed hierarchy may need to be adjusted in practice, either because of local features of the talk or because of the individual needs of learners. For example, some children may benefit from entirely errorless learning techniques which have proved effective for children with significant needs (Mueller, Palkovic \& Maynard, 2007). 
Key to ensuring that the scaffolding matches the specific needs of the student is the ability of the TA to set small goals in relation to the overall task and then accurately assess what the student is able to achieve independently, in order to negotiate and renegotiate progress towards these goals (Rodgers, 2004; Tharp \& Gallimore, 1988). This requires building a picture of the 'performance characteristics' of the learner at that moment in time (Wood, Bruner \& Ross, 1976), including the independent strategies that they are able to draw on, and the success of these strategies. It is therefore important that students are encouraged to 'think aloud' in terms of articulating their self-support strategies while working, allowing informed decisions to be made by the TA as to the type of support move required. This fosters independence by allowing students to lead the interaction, with fine calibrated support offered only when required. It also provides the opportunity for the TA to offer heuristic scaffolding by encouraging the use of known self-supporting strategies and model those not yet in use. Over time this may also provide information about the strategies that the student needs to practise, supporting the task design (planning) process. In a group situation, encouraging the use of thinking aloud in this way has the added benefit of providing models for other students, both in relation to the strategy being used and articulating the on-going thinking about the problem.

Having considered heuristic scaffolding practices in detail, it is important also to consider how TAs should be prepared for this important role. Indeed, the implications for the school system are profound. Whether TA classroom deployment involves one-to-one, small group or a whole class 'roving' role does not matter; from our data the same principles of scaffolding apply across all teaching contexts. In terms of preparation, it is vital that time is set aside for the teacher to brief the TA before the lesson (Blatchford, Russell \& Webster, 2012). We recommend that the briefing includes the key concepts of the lesson and any that might present particular difficulties for the students as well as key learning strategies that are relevant to the lesson content.

Before entry to the classroom, however, TAs require knowledge, understanding and skills to deliver heuristic scaffolding. The following ideas are therefore presented for trainers. First of all, a clear definition of scaffolding is needed, and we propose the following: 
'..an act of teaching that (i) supports the immediate construction of knowledge by the learner; and (ii) provides the basis for future independent learning of an individual.’ Holton \& Clarke, 2006, 131.

This definition emphasises two key concepts: the importance of contingency and, secondly, the need to drive the student towards independence as opposed to increasing dependency on the TA. In terms of the first part of the definition, the data amply show examples of contingency in action. However, consistent with other studies, it was much harder to demonstrate that fading and transfer of responsibility had occurred (van de Pol et al., 2010). Future research could examine this through the use of longitudinal data collection, given the same TA and similar tasks. As troubles and repair are such key features of the talk between TAs and learners with SEN, further studies using CA are warranted. The distinction between correction (high adult control) and other-initiated repair (that fosters learner independence) has already been shown to be very important for teachers (Radford, 2010b). It would be valuable to explore the implications of this distinction for TAs.

Given the messages emerging from the DISS project, developing the techniques and strategies outlined in this paper contributes to improving the quality of TAs’ pedagogical interactions with pupils, and is a necessary component of maximising the use of TAs. The Wider Pedagogical Role model, developed to explain the findings from the DISS project, provides a robust framework that situates TA talk (what the model refers to as 'practice') within a wider context on how TAs are deployed and prepared for their role (Webster et al., 2011; Blatchford et al., 2012). If TAs are to retain a pedagogical role in schools, more needs to be done than simply modifying TA-to-pupil interactions. A book of guidance for school leaders and teachers produced on the basis of findings from the EDTA project makes it clear that school leaders must consider how existing models of TA deployment maximise or impede the opportunities for quality talk, and how TAs can be more appropriately trained and prepared prior to lessons (Russell, Webster \& Blatchford, 2013). Our key message is that the TA must contribute to the fundamental educational aim of laying the foundations of independent learning. The theoretical model suggested in this paper offers a solid framework for future research as well as examples in practice that are vital for training purposes. 


\section{References}

Blatchford, P., Russell, A. \& Webster, R. (2012). Reassessing the impact of teaching assistants: How research challenges practice and policy. Oxon, UK: Routledge.

Blatchford, P., Kutnick, P., Baines, E. \& Galton, M. (2003). Toward a social pedagogy of classroom groupwork. International Journal of Educational Research, 39, 153-172.

Bosanquet, P. (2012). Turn taking, repair and topic practices in teaching assistant led literacy intervention session. Unpublished PhD thesis: University of London.

Cambridge Dictionaries Online http://dictionary.cambridge.org/dictionary/british/heuristic accessed on 9/05/2012

Causton-Theoharis, J., Giangreco, M., Doyle, M. \& Vadasy, P. (2007). Paraprofessionals: the "sous-chefs" of literacy instruction. Teaching Exceptional Children, 40, 57-62.

Corbin, J. \& Strauss, A. (2008). Basics of qualitative research: techniques and procedures for developing grounded theory ( $3^{\text {rd }}$ ed.). London: Sage.

Daniels, H. (2001). Vygotsky and pedagogy. London: Routledge.

Department for Children Schools and Families (2007). Early Literacy Support. Nottingham: DCSF Publications.

Department for Education and Employment (1999). The National Literacy Strategy: Additional literacy support module 2. London: DfEE.

Department for Education and Skills (2003). Time for standards: Guidance accompanying the section 133 regulations issued under the Education Act 2002. London: Department for Education and Skills.

Department for Education (2012). Statistical first release (SFR06/2012): School workforce in England (provisional) November 2011. Online. Available at:

http://www.education.gov.uk/researchandstatistics/statistics/recentreleases/a00205723/school -workforce-in-england-provisional-nov-2011. (accessed 14.05.12).

Giangreco, M. F.\& Doyle, M. B.(2007).Teacher assistants in inclusive schools. In L. Florian (Ed.), The SAGE handbook of special education (pp. 429-439). London: Sage.

Maloch, B. (2002). Scaffolding student talk: one teacher's role in literature discussion groups. Reading Research Quarterly, 37, 94-112.

Hacker , D. \& Tenent, A. (2002). Implementing reciprocal teaching in the classroom:

Overcoming obstacles and making modifications. Journal of Educational Psychology, 94, 699-718. 
Holton, D. \& Clarke, D. (2006).Scaffolding and metacognition. International Journal of Mathematical Education in Science and Technology, 37, 127-143.

Mercer, N., Dawes, L., Wegerif, R. \& Sams, C. (2004). Reasoning as a scientist: Ways of helping children to use language to learn Science. British Educational Research Journal, 30, 359-377.

Meyer, D. \& Turner, J. (2002). Using instructional discourse analysis to study the scaffolding of student self-regulation. Educational Psychologist, 37, 17-25.

Mueller, M., Palkovic, C. \& Maynard, C. (2007). Errorless learning: Review and practical application for teaching children with pervasive developmental disorders. Psychology in the Schools, 44, 691-700.

Myhill, D. (2006). Talk, talk, talk: teaching and learning in whole class discourse. Research Papers in Education, 21, 19-41.

Myhill, D. \& Warren, P. (2005). Scaffolds or straitjackets: critical moments in classroom discourse. Educational Review, 57, 55-69.

Newman, D., Griffith, P. \& Cole, M. (1989). The construction zone: Working for cognitive change in school. Cambridge: Cambridge University Press.

Pentimonti, J. \& Justice, L. (2010).Teachers' use of scaffolding strategies during read-alouds in the pre-school classroom. Early Childhood Education Journal, 37, 241-248.

Radford, J. (2010a). Adult participation in children's word searches: on the use of prompting, hinting and candidate offers. Clinical Linguistics and Phonetics, 24, 83-100.

Radford, J. (2010b). Practices of other-initiated repair and correction in SSLD classroom discourse. Applied Linguistics, 31, 25-44.

Radford, J., Blatchford, P. and Webster, R. (2011). Opening up and closing down: how teachers and TAs manage turn-taking, topic and repair in mathematics lessons. Learning and Instruction, 21, 625-635.

Rodgers, E. M. (2004). Interactions that scaffold reading performance. Journal of Literacy Research, 36, 501-532.

Rubie-Davies, C., Blatchford, P., Webster, R., Koutsoubou, M. \& Bassett, P. (2010). Enhancing student learning? A comparison of teaching and teaching assistant interaction with pupils. School Effectiveness and School Improvement. 21, 429-449.

Russell, A., Webster, R. \& Blatchford, P. (2013). Maximising the impact of teaching assistants: Guidance for school leaders and teacher. Oxon: Routledge.

Spooner, F., Knight, V., Browder, D. \& Smith, B. (2012). Evidence-based practice for teaching academics to students with severe developmental disabilities. Remedial and Special Education, 33, 374-387. 
The Sutton Trust (2012). Pupil premium money will have limited impact on poorer pupils, teacher survey suggests. Available online at http://www.suttontrust.com/news/news/pupilpremium-limited-impact-on-poorer-pupils-teacher-survey. Accessed on 28th August 2012

Tharp, R. \& Gallimore, R. (1988). Rousing minds to life: teaching, learning, and schooling in social context. Cambridge: Cambridge University Press.

Van de Pol, J., Volman, M. \& Beishuizen, J. (2010). Scaffolding in teacher-student interaction: a decade of research. Educational Psychology Review, 22, 271-296.

Vygotsky, L. S. (1978). Mind in society: the development of higher psychological processes. Cambridge, MA: Harvard University Press.

Vygotsky, L. S. (1981). The genesis of higher mental functions. In J.V. Wertsch (Ed.), The concept of activity in Soviet psychology (pp. 144-188). Armonk, NY: Sharpe.

Webster, R., Blatchford, P., Bassett, P., Brown, P., Martin, C. \& Russell, A. (2010). Double standards and first principles: framing paraprofessional support for pupils with special educational needs. European Journal of Special Needs Education, 25, 319-336.

Webster, R., Blatchford, P., Bassett, P., Brown, P., Martin, C. \& Russell, A. (2011). The wider pedagogical role of teaching assistants. School Leadership and Management, 31, 3-20.

Webster, R., Blatchford, P. \& Russell, A. (2012). Challenging and changing how schools use teaching assistants: Findings from the Effective Deployment of Teaching Assistants project, School Leadership \& Management, first published online, 9 October 2012 (iFirst).

Wood, D., Bruner, J. S. \& Ross, G. (1976). The role of tutoring in problem solving. Journal of Child Psychology and Child Psychiatry, 17, 89-100. 
Figure 1: Conceptual model of scaffolding

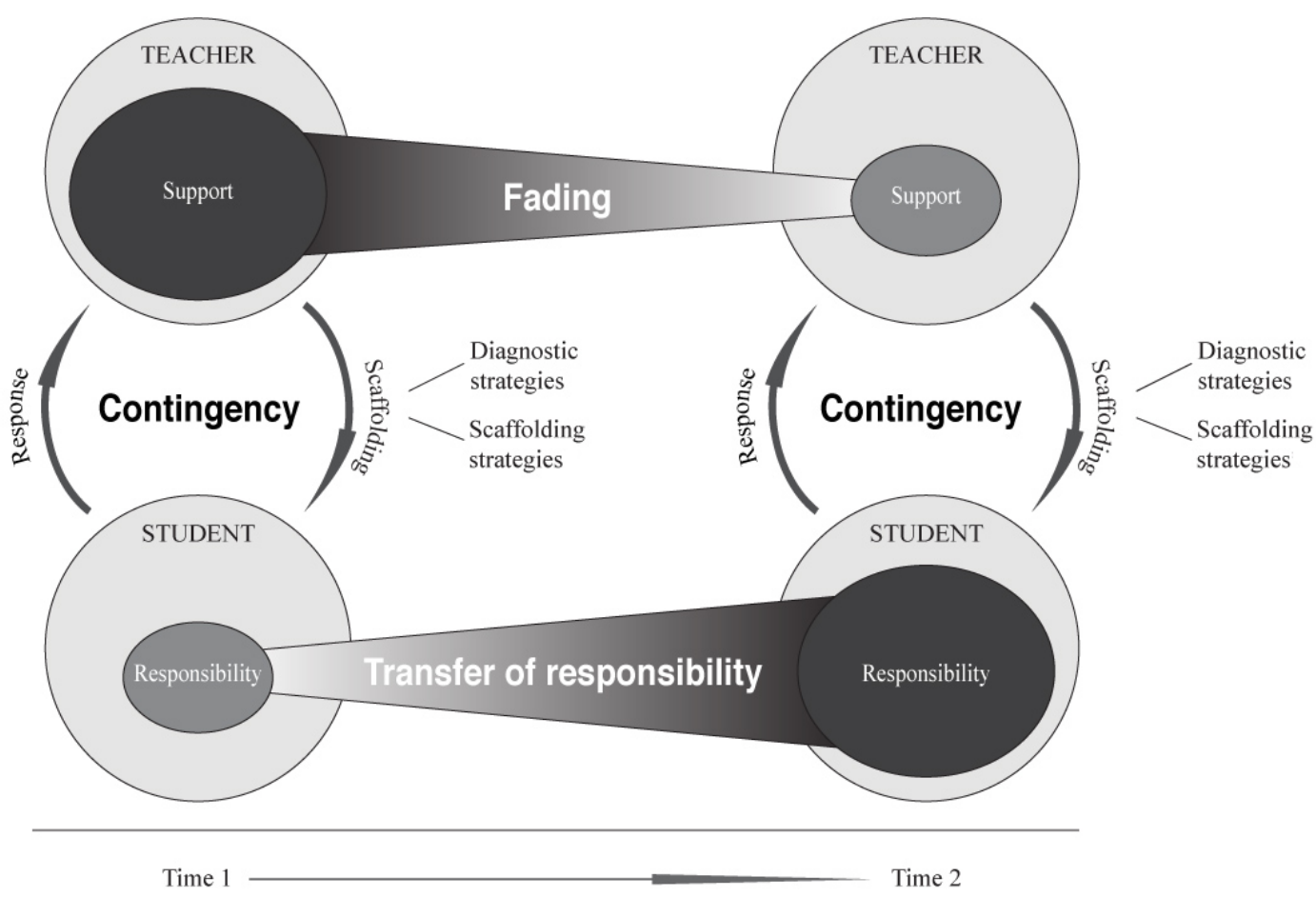

Van de Pol, Volman \& Beishuizen, 2010: 274, (with kind permission of the authors) 
Figure 2: Hierarchy of heuristic scaffolding

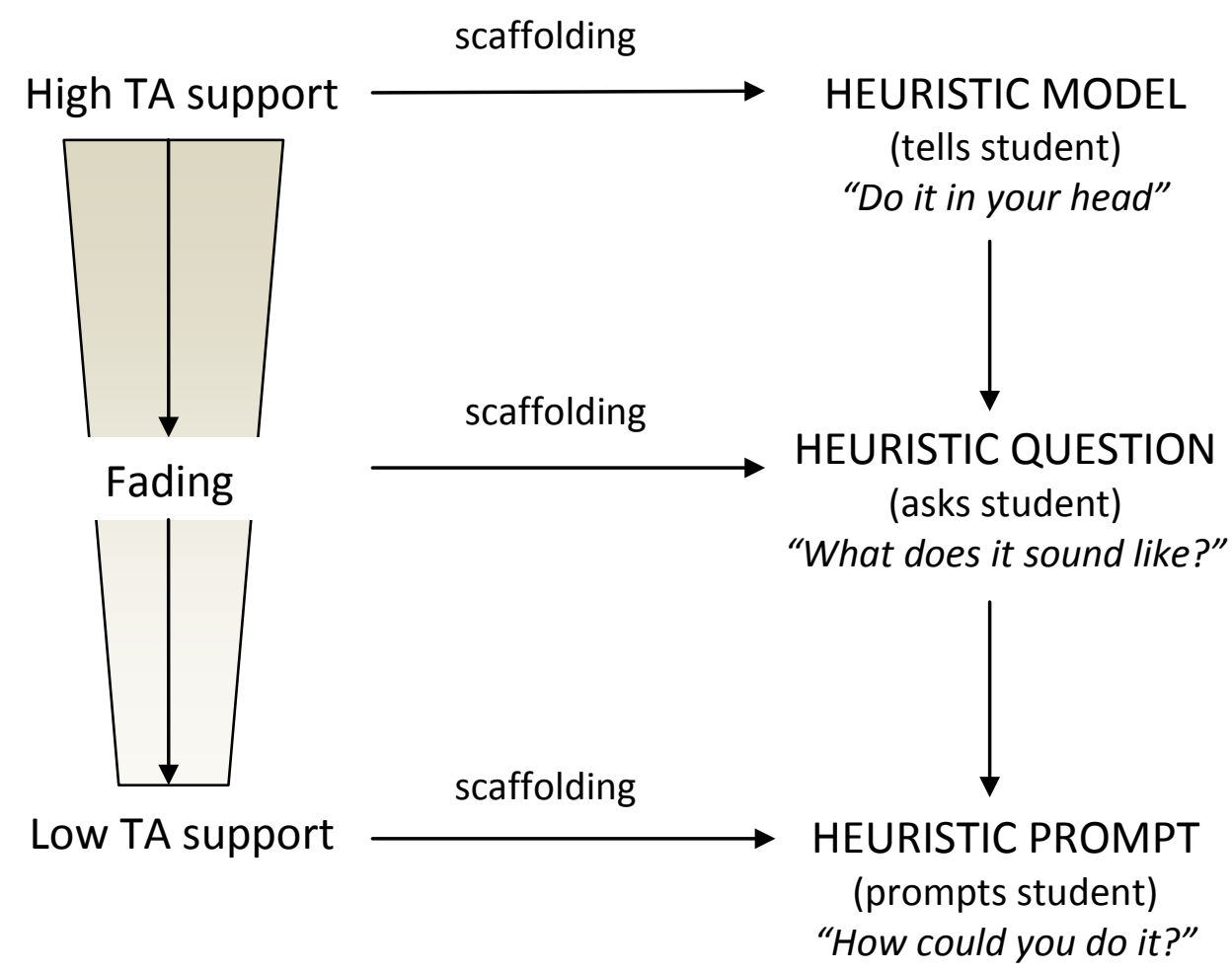

